\title{
Study on Psychological Activities and Physiological Skills of Singing in Vocal Music Teaching
}

\author{
Weiyi Hao, Yun Jing, Lijuan Li \\ Music Department, Xingtai University, Xingtai 054001, China
}

Keywords: vocal music teaching; singing; psychological activity; physiological skill

\begin{abstract}
: peculiar singing process in vocal music teaching cannot be separated from deep-level metal domination. Diversified psychological activities will accompany with singing process. Peculiar skills of singing physiology are dominated by potential psychology. The skill is the external of cognition. Psychological activities and physiological skills related to singing are dialectical mutually. Such relevance of the two constructs interactive dialectical relationship. Proper path preset for vocal music teaching should be able to integrate physiological control, correspond to psychological adjustment, improve singing level and create the optimal value of vocal music.
\end{abstract}

The art created by vocal music has comprehensive properties. Unique skills and thoughts are contained in vocal music singing. Vocal music covers emotion and adopts singing skills under comprehensive architecture. Singing effects are gained through complex physiological and psychological activities. The effects of song singing are closely related to physiological elements at technical level and cannot be separated from proper psychological effects. Thus, it is necessary to clearly know series of rules represented by psychological activities and make potential psychological cognition run through daily vocal music teaching.

\section{Psychological and physiological relevance}

(I) To specify the relevance of the two

Proper psychological perception of vocal music singing is closely connected with physiological skills. Multi-level psychological activities represent brain response to things. The root psychology depends on is usual concerted activity of nervous system. Vocal music singing and peculiar thinking activity have clear relevance. Under the command of brain, proper vocal organs shall be able to cooperate with each other and jointly produce voice. The change of psychology has direct relationship with physiological skills. For example, the singers who sing the first time will get into a panic and their spirit is nervous. Under such state, singing organs often become rigid, which will result in organ imbalance or polypnea. Thus, they fail to give play to the preset singing level.

Singing activities in vocal music category highlight integrality. High-level singing effect integrates sound production, resonance, smooth breathing, the optimal mentality and accurate expression. Multi-element synergy can create the optimal effect. Multiple elements in vocal music highlight mutual restriction and relevance. Only harmony in the whole range can mobilize detailed parts and make singers put into singing. If the imbalance happens to the proper part, macroscopic perspective should be preset to classify it into body imbalances in the entire architecture. We cannot focus on one side, but should cooperate with the entirety and properly solve difficulties.

(II) Detailed stages of skill formation

Proper Psychological and physiological formation stages can be subdivided into three periods:

The first period is diffusion stage of the excitement process in the initial stage. Those who just learn to sing experience internal and external feeling under strong situation. Such strong feeling will impact original nerve center, stimulate a large range of excitement within the brain cortex, and create restriction zone. Such proper diffusion of excitement and restriction is not equipped with adept skills. Thus, singers often have rigid limbs and fail to balance the entirety. So, the notes they make are not smooth.

The second period is differentiation restriction within the internal category. Such restriction 
gradually expands and confirms clear differentiation. During differentiation enhancement, singing methods with error characteristics are removed. Singers' original skills improve, and the singing state is balanced. The sound will become more smooth and centralized. Singers' original range expands, which creates root for follow-up higher development.

The third period is subsequent stabilization stage. In this stage, multiple activities of the body promote original harmony. The power of the body cortex is also consolidated. Singing stage under the general architecture gradually tends to harmony. At this moment, the singers integrate sound and emotion and create the optimal artistic conception.

\section{To explore the root of imbalance}

(I) Cognition deviation

Many students like music and can carefully identify singing skills. For original vocal music principles, students should clearly know them. However, when they really sing, they are usually nervous and fail to adopt suitable methods. The root of such malady is proper psychological imbalance which leads to unsmooth air flow and rigid body during singing. So, the sound is unpleasant to hear. For these students, teachers should assist them, confirm due correct cognition, get rod of technical concept under pure situation and accept common mentality.

(II) Mixture of excessive concerns

Many students have many distracting thoughts during singing. They usually consider they will lose face if they fail to sing correctly or fail to gain the expected result. If the song is difficult, such difficulty will be more prominent, and heavy psychological burden is added. Thus, daily skill training shall be combined with self-confidence cultivation. In vocal music teaching, teachers should add psychology and cultivate students with self-confidence. Students should be able to identify the optimal mentality, should not haggle over and should get rid of usual nervous mentality.

(III) Self-abasement trend

Students' physical and psychological quality will make differences prominent. The foundation of vocal music course will have differences. The maladies exposed in voice training are also different. For example, some students are timid. They feel very relaxed during, but they will be very nervous and their bodies become rigid suddenly during voice training. In the face of such students, teachers should not immediately ask them to practice. Before actual training, teachers should help students seek the root cause of being nervous, eliminate deep-level psychological burden, return to relaxed mood, clearly know the root of self-abasement and prudently analyze it. After these, students should take symptomatic treatment and return to due conventional mentality.

\section{Psychological adjustment function for physiology}

Psychological activities under positive situation can orderly adjust physiological skills. Such adjustment effects can be classified into the following levels:

(I) To create pleasant atmosphere

Before formal teaching, teachers should preset targeted talks, select the students with heavy pressure, talk about interesting topics or play relaxing music. This can create relaxing and pleasant atmosphere, enhance emotional resonance and dispel tension. In the teaching process, teachers should be good at applying humorous utterances to construct relaxing atmosphere and reduce mental pressure. During cultivating students' auditory sense, relatively simple songs with happy melody and heavy emotion should be selected.

Teachers should not just purely pay attention to skills, but also teach students to express their deep-level emotions with heart and drive sound production with accumulative heavy emotions, create beautiful environment and infect them. In this way, singing psychology under overall architecture can be adjusted, and meanwhile physiological skills can improve.

(II) To awaken positive mentality

In a broad sense, proper psychological cognition of singers drives physiological activities. Multi-level psychological elements involve extended exertion of physiological skills. For example, 
sometimes singers still sing a high pitch by virtue of natural level. However, when they are infirmed of the actual difficulty of the high pitch, it is very difficult for them to create the same level when they are asked to sing it again. Such prominent contrast is related to mentality and cognition. Thus, during singing, peculiar positive mentality should be awakened to accumulate sufficient self-confidence. Only in this way, in follow-up singing, students can confirm confidence, overcome barriers and gain double effects.

(III) To extend rich association

Positive psychological activities are also associated with rich association crated by depending on thoughts. For instance, diversified tone characteristics can be compared to peculiar shapes. During identifying the due sound production parts, association can be expanded in such way: tone comes from a part in the body, rather than the mouth. For example, it is very hard for some students top open their throats. Then, such association can be established: they can imagine that the mouth is located in the throat, and that can promote adjustment of multiple organs and improve the skills.

\section{To coordinate cultivation approaches}

The survey results show the optimal technology under the whole situation can be created and melodious songs can be sung only when the mentality is adjusted well. Singers' peculiar psychological cognition and corresponding physiological skills are set to the important links which should be especially cultivated. In daily teaching, teachers should preset coordination thought under the whole architecture, orderly integrate fundamental skills, cognition mentality and quality by depending on continuous training. To be more specific, peculiar promotion paths of comprehensive quality include the following links:

(I) To attach important to voice training

Peculiar practice of voice training specifies this rule: slight voice training can relax both ones body and mind and make one naturally open the voice path. Under such state, breath will gradually sink. Then, the oral cavity and thoracic cavity are opened naturally. Such voice training connects multi-level sound pronunciation zones and reconcile consistent sound production parts, solve usual breath rising and gain resonance. Natural relaxing skills can help singers to relax on the whole.

(II) To adjust mentality anytime

The training within the category of vocal music teaching should adopt entire perspective. Meanwhile, learners should relax their body and mind. Teachers should encourage students to be self-confident, boldly express themselves and get development. Students should particulate in vocal music practice, train their body and mind on stages and express their unique skills. Besides, they should neither focus on individual gains and loss nor concern too much about their comments. Students can gain long-term progress only after they persuade themselves. When really singing, they should keep pleasant mood and calm mentality. Without the need of considering complex singing skills, as long as they trust themselves, they can overcome all setbacks, eliminate nervous mood and express their emotions during singing. In this way, they can avoid potential nervous experience and sing wonderfully with a silver voice and deep feeling.

(III) To transfer emphasis

Singers' physiological tension is associated with potential nervous experience. If mental tension is removed, partial tension of the body can also be eliminated. For example, before singing, such problem may be proposed: whether relaxed mentality can help me sing melodious songs? Such present question can transfer original lime light, eliminate nervous mood and gain initial relaxation.

(IV) To identify rhythm

Vocal music teaching under traditional situation adopts dull and boring teaching process. Under such situation, classroom passion and joys are lost. The teaching emphases of the teaching program will become pressures and give rise to heavy mental burden. To change this stage, it is required to integrate rhythm and preset song rhythm. Rhythm means music is used to drive body movements. The body movements should have clear rules.

It is necessary to create graceful and vigorous shape-up exercises which can reconcile each movement according to the set music melody, corresponding emotional style. Rhythm and peculiar 
rhythm training can change usual vocal music training process and solve body tension in partial category.

(V) To create proper metaphor

Singers own unique subjective feeling when singing. Such imagination cannot be separated from metaphors. Accurate and vivid metaphors can better make singers relaxed and be more easily accepted than usual technical explanations. If teachers can skillfully apply metaphors in vocal music classroom, they will gain outstanding effects. For example, diversified notes can be compared to visual patterns. Tone characteristics can be shown with the help of visual feeling. Usually, the principles of vocal music teaching will cover how to cooperate with muscle movement and mobilize sound production etc. Actually, these fundamentals can be made to vivid metaphors. For example, teachers may ask students to imagine that they are smelling flowers' fragrance in the forest. Thus, they should take a deep breath. This not just removes tension, but also assists students in clearly knowing sound production skills for the convenience of follow-up extended learning.

(VI) To drive with emotion

In many stages, students fail to accurately make a high pitch. To solve this difficulty, high pitches can be prepared in graceful songs. Or special section containing this high pitch can be sought from graceful melodies screened out. Such melodies screened out can serve as training foundation. After students are familiar with this song, they will put into their emotion during singing this song. In this way, they forget sense of tension and sing the song well. After that, teachers should teach students voice training skills and let them own such control cognition. In follow-up random singing, they will obtain good effects.

\section{Matters needing attention}

Internal psychological activities and fundamental physiological skills are significant parts of singing. In daily teaching, the training approaches selected can be divided into multiple types. The peculiar training process of each teacher should be checked by practice to identify effectiveness. To identify peculiar effects, it is required to put particular emphasis on deep-level psychological counseling. For instance, during analyzing complex singing skills, students can recite the prepared lyrics and elocnte the lyrics. Such natural sound production is convenient for profound memorization. After students recite the prepared lyrics, teachers should guide students to chant the lyrics like singing. This converges to original physiological voice and voice in singing.

In order to really integrate physiology and psychology, students should get rid of usual utilitarian mentality and clearly know the fundamental objective of singing practice is to boost original aesthetic level, instead of purely creating performance. Singing relaxingly eliminates tension trouble.

\section{Conclusions}

In vocal music class, students should clearly know internal correlation between physiological skills and psychological cognition as well as the significant value of psychological activities. Teachers should focus on identifying students' cognitive disposition and adopt scientific methods to cultivate the optimal comprehensive quality. The fundamental skill of singing is physiological skill. Deeper-level singing guidance is psychological experience. It is necessary to attach importance to psychological and emotional changes under potential situations, stimulate vocal music interest and get singing effects as expected.

\section{References}

[1] Zhang Qiofeng, Exploration of psychological activities and physiological skills of singing in vocal music teaching [J]. Journal of Hebei Normal University (Science of Education), 2009 (05), 
[2] $\mathrm{Xu}$ Long, Study on psychological activities of singing in vocal music teaching [J]. Music Creation, 2013 (02), 03:186-187

[3] Mao Huilin, Study on vocal music singing psychology [J]. Journal of Hubei Adult Education Institute, 2010 (06), 01:84-85

[4] Wang Yuan, Discussion on singers' psychological quality and its cultivation in vocal music teaching [J]. Journal of Jiangxi Normal University, 2012 (11), 04:120-122+142

[5] Wang Kaige, Discussion on relationship between singing physiology and psychology in vocal music teaching [J]. Beauty \& Times, 2013 (07), 09:63-64 